Research Article

\title{
Investigation of the Models of Flow through Fractured Rock Masses Based on Borehole Data
}

\author{
Long Tan $\mathbb{D}^{1},{ }^{1}$ Wei Xiang, ${ }^{1}$ Jin Luo $\mathbb{D}^{1},{ }^{1}$ Qingbing Liu $\mathbb{D}^{1},{ }^{1}$ and Xu Zuo ${ }^{2}$ \\ ${ }^{1}$ Faculty of Engineering, China University of Geosciences, Wuhan 430074, China \\ ${ }^{2}$ China Petroleum Engineering \& Construction Corporation, North China Company, Beijing, China \\ Correspondence should be addressed to Qingbing Liu; qingbing@cug.edu.cn
}

Received 10 January 2020; Revised 14 May 2020; Accepted 22 May 2020; Published 10 June 2020

Academic Editor: Robert Černý; cernyr@fsv.cvut.cz

Copyright (c) 2020 Long Tan et al. This is an open access article distributed under the Creative Commons Attribution License, which permits unrestricted use, distribution, and reproduction in any medium, provided the original work is properly cited.

When only limited borehole data are available, making optimum use of the existing data is crucial for performing a preliminary assessment of the investigated site. In this paper, the relationships between the borehole data and the permeability coefficient were first analyzed. These relationships were then used to establish a model for estimating the permeability coefficient of rock mass that takes into account the influence from the confining pressure on the seepage flow. The proposed model can reduce the number of hydraulic tests which are time consuming and very costly and allow the determination of change in the permeability coefficient throughout the borehole. The flow model could assist in providing important references for selecting an appropriate permeability coefficient in hydrogeological simulation and in evaluating the condition of large cracks developed in boreholes. In general, the seepage flow model developed in this study will contribute to the design practice of a tunnel project constructed in fractured rock masses.

\section{Introduction}

The success of underground water-sealed oil storage projects depends on two major factors: the stability of the surrounding rock and the condition of the water seal. Among them, the water seal condition is considerably affected by the underground seepage field. A commonly used method of establishing the underground seepage field model during construction is obtaining the rock permeability coefficient of a specific area using in situ tests in the borehole $[1,2]$.

As a rock type of low permeability, natural granite rock mass comprises discrete blocks of intact rock and discontinuities, such as factures, fissures, and joints [3]. Its permeability is mainly controlled by the development state of discontinuities. Therefore, evaluating the groundwater seepage characteristics in granite areas is essential for assessing the development level of fissures within underground rock masses.

During the construction process, and in particular, the prefeasibility stage when there is only limited borehole data available, it is often difficult to evaluate the seepage field of the site with a small amount of data [4]. Attempts to obtain more borehole data by the hydraulic pressure test will require a considerable amount of time and cost, and therefore exploring the relationship between available borehole data and fracture seepage and then applying it to estimate the permeability coefficient can effectively reduce the number of hydraulic pressure tests and greatly save construction costs.

The research of fracture seepage often starts from a series of simplified models. The goal of researchers is to deduce the general formula from various models. Scholars from various countries have done a lot of research on fracture seepage. Many scholars consider the influence of the rough fracture surface from different aspects and introduce the roughness influence coefficient into the cubic law to analyze seepage characteristics of the rough fracture [3,5-8]. With the rapid development of numerical simulation technology, the establishment of a three-dimensional or two-dimensional model of the fracture surface to describe the surface morphology characteristics of the fracture surface and its application in seepage calculation has become a popular method of studying fracture seepage [9-12]. The theory of 
the lattice Boltzmann method is usually used to establish a numerical model to simulate the seepage of cracks in rough rock mass. This became one of the effective numerical research tools in solving the seepage problem of cracks in rough rock mass [13-17].

The research methods mentioned above are generally too sophisticated for engineers to use in practice. A convenient method is now put forward in this article, which is straightforward and accurate enough for engineering application. In this study, we established the relationship between the parameters of the structural plane in the fractured rock mass and the permeability coefficient of the fractured rock mass by analyzing several crack indices such as aperture and inclination angle.

The studied site is located in a specific region in Yantai, Shandong, as shown in Figure 1. It is geographically located in the Shandong Peninsula of China, separated from Dalian by the sea and connected to Shanghai and Qingdao by land routes. The proposed underground water-sealed oil storage project is located in a hilly area with a tectonically denudated terrain. The middle region is covered by convex hills, which possess deep cut slopes revealing bare rocks at local gullies. The surrounding terrain is a hilly alluvial plain with a low altitude and a gentle slope. The mound is composed of coarse-medium grained porphyritic monzogranite and biotite monzogranite. The bedrocks at the hilltop and the slope are mostly exposed directly to ambient weather with certain local regions covered by a thin layer of residual soil.

According to on-site geological mapping and geological drilling, the regional exposed strata are rocks formed at the Quaternary period during the Cenozoic era and a large area of intrusive rocks. The intrusive rocks identified in the target site are primarily Luliang, Sinian, and early Yanshanian intrusive rocks. In addition, some diorite-like porphyry, lamprophyre, and granite porphyry rocks also invaded the Luliang and Yanshanian magmatic rocks in the vein shape.

\section{Fracture Seepage Model Based on Borehole Data}

2.1. Theoretical Basis of Permeability Coefficient of Fractured Rock Mass. Poiseuille derived a theoretical formula to describe the motion of a viscous incompressible fluid in the gap between smooth parallel plates under homogeneous and constant velocity conditions; it is expressed as [18]

$$
u=\left(\frac{g b^{2}}{12 v}\right) J,
$$

where $u$ is the flow rate $(\mathrm{m} / \mathrm{s}), g$ is the gravitational acceleration $\left(\mathrm{m} / \mathrm{s}^{2}\right), b$ is the width between smooth parallel plates $(\mathrm{m}), v$ is the kinematic viscosity coefficient of water $\left(\mathrm{m}^{2} / \mathrm{s}\right)$, and $J$ is the hydraulic gradient.

Snow conducted a parallel plate fissure seepage test and suggested the popular cubic law for fractures $[19,20]$ :

$$
q=\left(\frac{g b^{3}}{12 v}\right) J,
$$

where $q$ is the flow per unit length $\left(\mathrm{m}^{2} / \mathrm{s}\right)$.

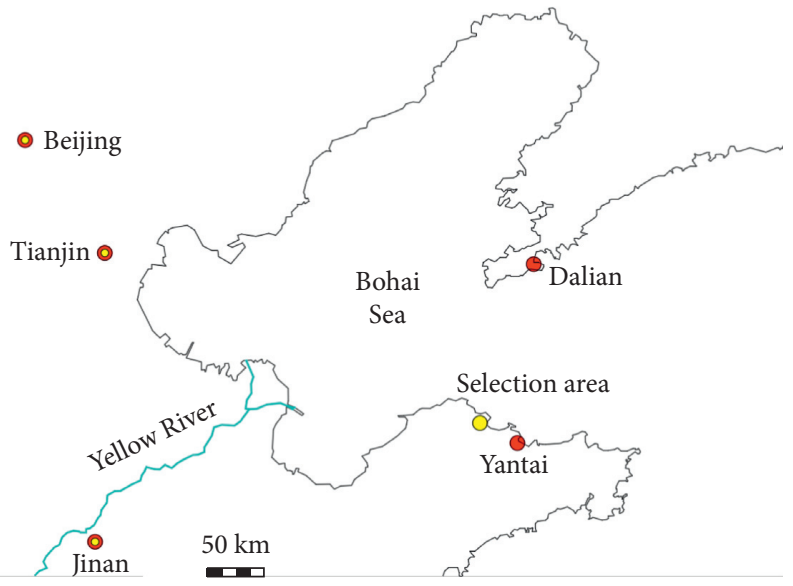

FIGURE 1: Geographic schematic map of the selected site of the water-sealed storage caverns in the Yantai city of Shandong province in China.

The width between two parallel plates can be treated as the crack width of the ideal fractured rock layer. When the liquid is in laminar flow, the average flow rate is given by

$$
u=\frac{B^{2}}{12} \cdot \frac{\gamma}{\mu} J,
$$

where $B$ is the aperture of the crack $(\mathrm{m}), \gamma$ is the volumetric weight $\left(\mathrm{N} / \mathrm{m}^{3}\right)$, and $\mu$ is the dynamic viscosity of water $(\mathrm{Pa} \cdot \mathrm{s})$.

If the crack system is treated as a lot of straight cracks and all the apertures are considered equal, then the flow velocity along the line of intersection of the fracture group is given by

$$
v=\frac{N B^{2}}{12} \cdot \frac{\gamma}{\mu} J,
$$

where $v$ is the total flow velocity of all the cracks $(\mathrm{m} / \mathrm{s})$ and $N$ is the number of the cracks.

Therefore, the permeability coefficient can be calculated by

$$
K=\left(\frac{N B^{2}}{12}\right)\left(\frac{\gamma}{\mu}\right),
$$

where $K$ is the permeability coefficient $(\mathrm{m} / \mathrm{s})$.

Figure 2 shows the schematic of the fracture distribution in the borehole. As shown in the figure, we can always obtain the aperture and angle between the crack and the horizontal direction regardless of the shape of the fracture revealed by the borehole.

In the smooth parallel-plate model, the fracture system is treated as multiple equal-width and flat-fracture groups. In real engineering practices, however, the cracks in the fracture system revealed by drilling usually exhibit different inclination angles, a variety of aperture, and rough surfaces. Some of the cracks are even packed with filling materials. Therefore, several additional factors neglected by the smooth parallel plate model need to be considered when analyzing the permeability coefficient in engineering practices. These 


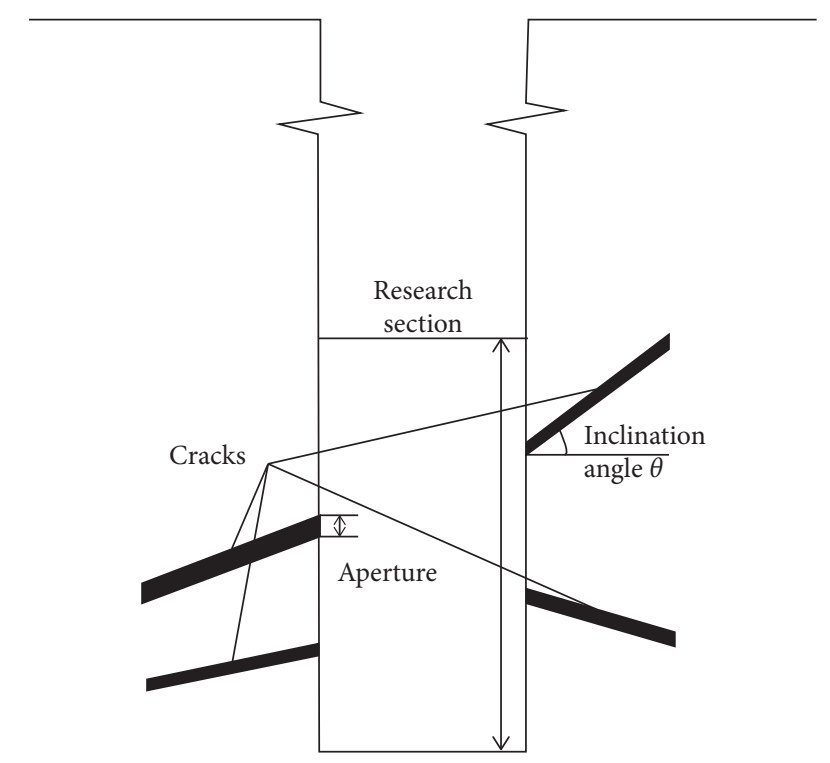

FIGURE 2: Schematic map of fracture distribution during the borehole hydraulic pressure test.

factors include the inclination angle, roughness, and aperture of the fracture.

2.2. Parameter Selection at the Structural Plane. By analyzing the results of the hydraulic pressure test performed in the borehole and the fracture development characteristics of the corresponding section, several factors affecting the permeability of the rock mass can be inferred.

The results of the borehole TV (Figure 3) can be used to extract basic fracture information, as shown in Figure 4.

According to the picture of the borehole televiewer, the altitude difference of the crack can be calculated. Given the known diameter of the drill hole, the inclination angle can be obtained. On the other hand, the aperture could be observed from the picture.

2.2.1. Aperture of the Crack. The crack aperture revealed by the borehole is not equivalent to the hydraulic aperture of the seepage flow through the crack. However, these two parameters can be connected to each other based on Barton's empirical equation [21]:

$$
a_{h}=\frac{a_{m}^{2}}{\operatorname{JRC}^{2.5}}
$$

where $a_{h}$ is the equivalent hydraulic aperture $(m), a_{m}$ is the mechanic aperture $(m)$, and JRC is the roughness coefficient.

Though this equation yields an approximation, the aperture of the crack can still be used to reflect the aperture of the seepage channel to a certain extent, and thus it reflects the seepage capacity of the channel.

\subsubsection{Inclination Angle Index at the Structural Plane.} The distribution of the inclination angle at the structural plane can reflect the average direction of the inclination angle distributed in the study area. This direction can reflect

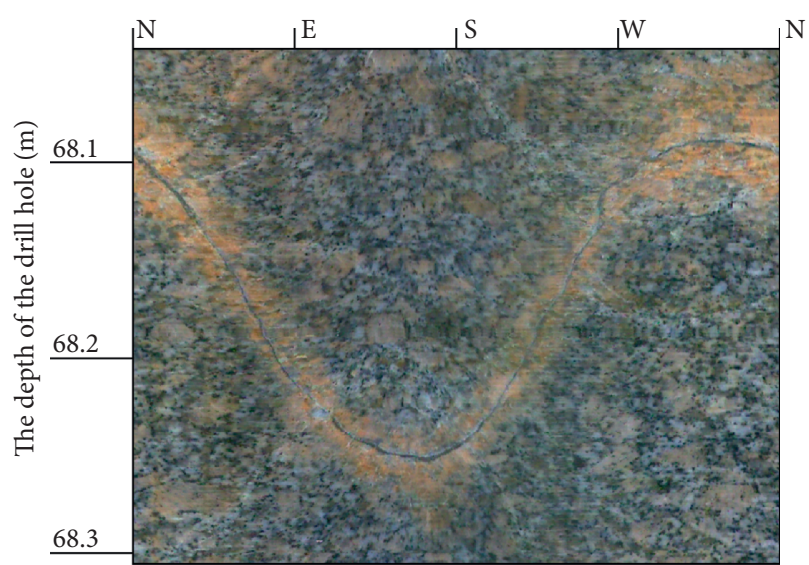

Figure 3: Picture of the borehole televiewer.

the effective seepage path in the target area in the field of seepage research. There should exist a certain relationship between the distribution index of the inclination angle at the structural surface and the permeability coefficient itself.

According to the established model, a change in the inclination angle will affect the length of the seepage path. Therefore, the permeability coefficient associated with this path will be reduced by $\cos \theta$ owing to the variation in the crack inclination angle. Thus, $\cos \theta$ is proposed as the inclination angle index at the structural plane.

2.2.3. Joint Roughness Coefficient (JRC). Barton established the straight-edge method of JRC measurement (Figure 5) on the basis of the in situ rock mechanics test, by which JRC is determined by measuring the surface fluctuation amplitude of the rock mass structural plane [22].

The crack development diagram shown in boreholes should theoretically adhere to the triangular function curve, as illustrated in the following function:

$$
y=A \sin (\omega x+t)
$$

where $A$ is the amplitude, $\omega$ is the angular velocity, and $t$ is the initial phase.

After measuring the amplitude from the drill televiewer, the basic form of the crack curve can be determined using the period of the curve function which can be calculated. Then, the curve could be used as the datum line to measure the fluctuation amplitude. The amplitude will be put on Barton's straight edge figure to obtain the final JRC, as shown in Figure 6.

\section{Model Development}

Because the size of the water-sealed cavern is much larger than that of the crack in the borehole, the following formula valid for each crack is introduced to simplify the calculation:

$$
K=\frac{1}{12} \cdot \frac{\gamma}{\mu} B^{2} \cos \theta
$$

where $\gamma$ is the volumetric weight $\left(\mathrm{N} / \mathrm{m}^{3}\right), \mu$ is the coefficient of viscosity $(\mathrm{Pa} \cdot \mathrm{s}), \theta$ is the inclination angle of the crack $\left({ }^{\circ}\right)$. 


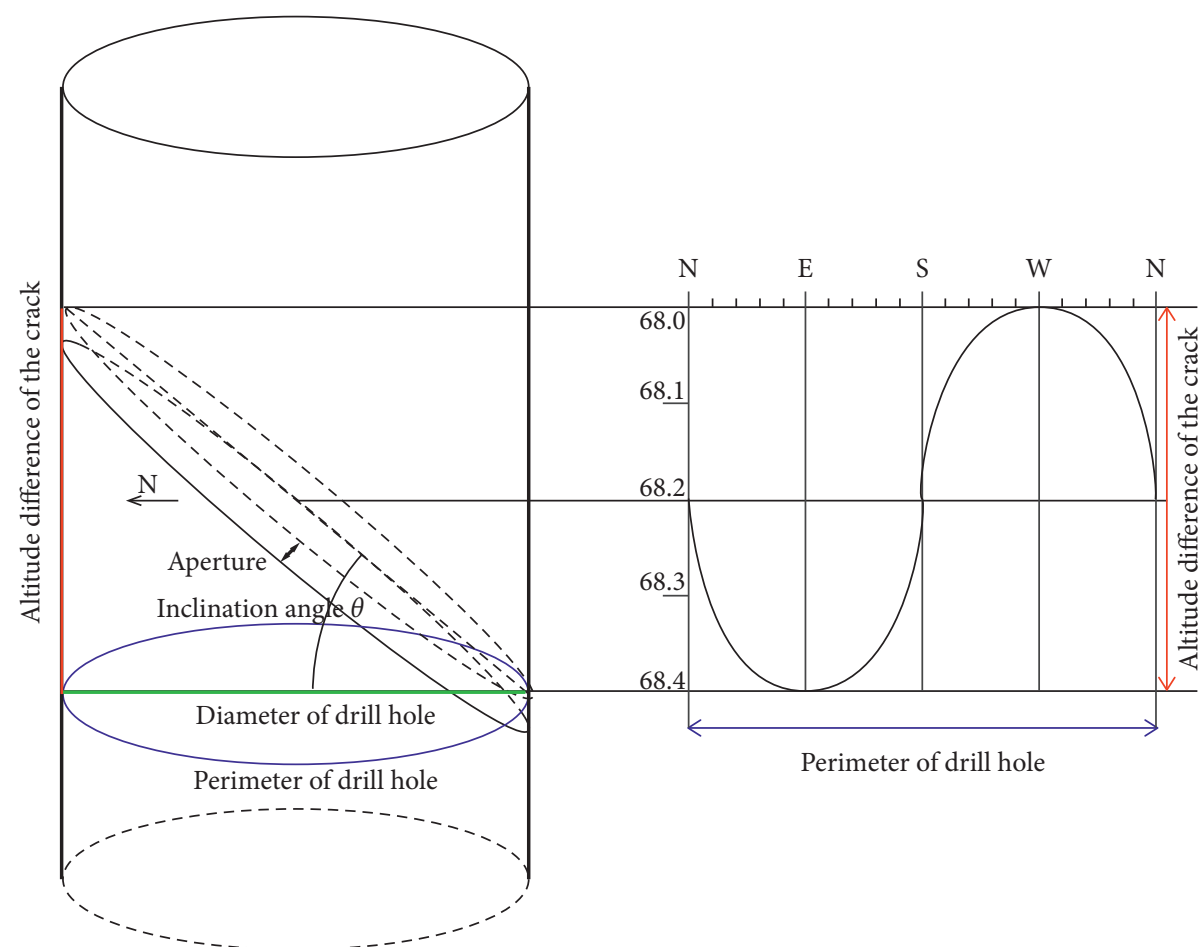

FIgURE 4: Schematic map of the borehole information extraction and calculation method.

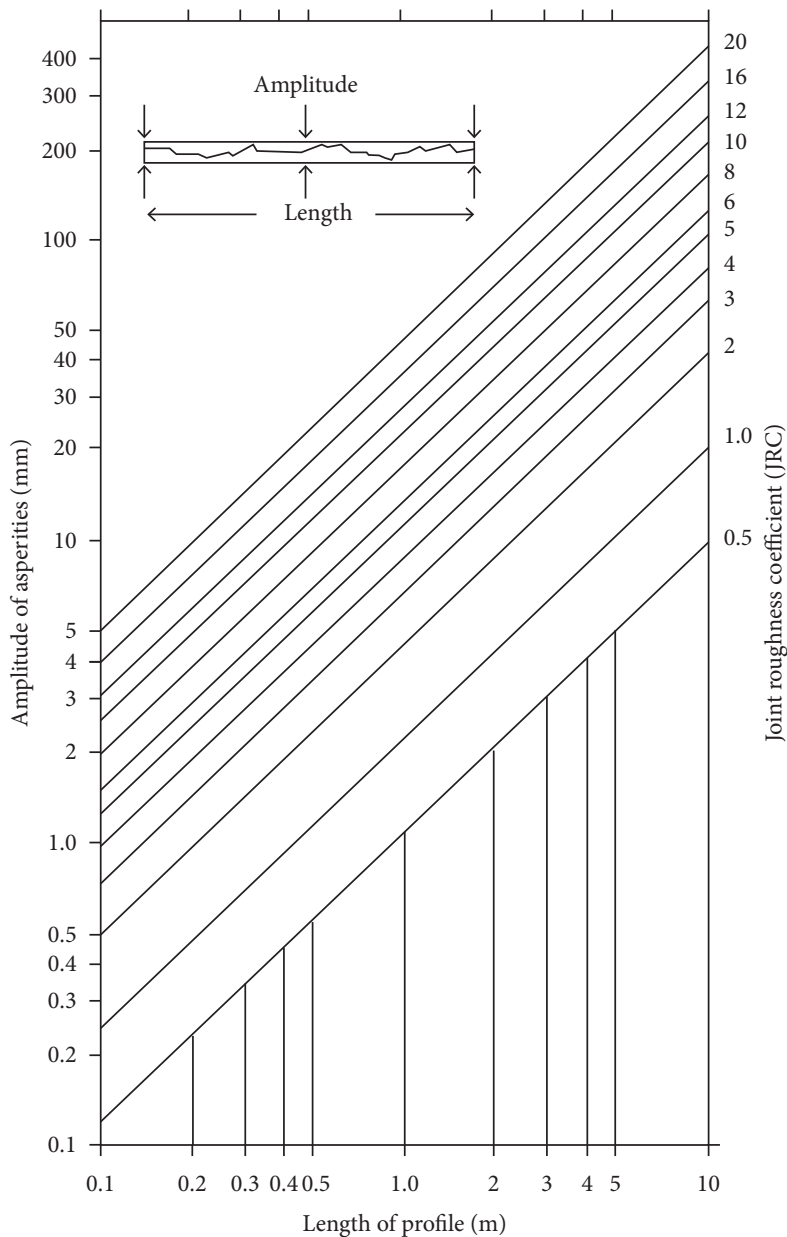

Figure 5: Barton's straight edge method.

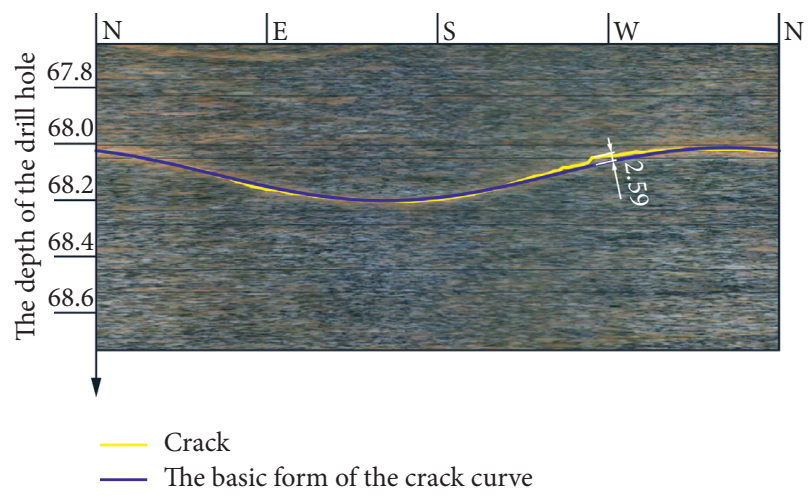

Figure 6: Schematic diagram for calculating fracture roughness.

Therefore, by combining this with the empirical equation proposed by Barton, equation (8) can be converted into

$$
K=\frac{1}{12} \cdot \frac{\gamma}{\mu} \frac{a_{m}^{4}}{\mathrm{JRC}^{5}} \cos \theta
$$

The mechanical aperture and the inclination angle index used in the equation can be obtained from the drilling video. These parameters allow us to calculate the permeability coefficient of an arbitrary crack and thus determine the seepage characteristic of any section in the borehole.

Based on the calculation, the permeability coefficient of the section in the drilling hole is the sum of the permeability coefficients of cracks in all directions:

$$
K_{m}=\sum_{i=1}^{n} \frac{1}{12} \cdot \frac{a_{m i}^{4}}{\mathrm{JRC}_{i}^{5}} \cdot \frac{\gamma}{\mu} \cos \theta_{i}
$$


TABLE 1: The results of water pressure tests in the borehole.

\begin{tabular}{|c|c|c|c|c|c|c|c|}
\hline \multirow{2}{*}{ Section no. } & \multicolumn{2}{|c|}{ Depth } & \multicolumn{2}{|c|}{ Altitude } & \multirow{2}{*}{ Length of test section (m) } & \multirow{2}{*}{ Permeability rate (Lu) } & \multirow{2}{*}{$\begin{array}{c}\text { Coefficient of } \\
\text { permeability }(\mathrm{m} / \mathrm{d})\end{array}$} \\
\hline & Start $(\mathrm{m})$ & End $(\mathrm{m})$ & Start $(\mathrm{m})$ & End $(\mathrm{m})$ & & & \\
\hline 1 & 5.13 & 15.50 & 124.10 & 113.73 & 10.37 & 10.08 & 0.10401 \\
\hline 2 & 15.13 & 25.50 & 114.10 & 103.73 & 10.37 & 8.80 & 0.09490 \\
\hline 3 & 25.13 & 35.50 & 104.10 & 93.73 & 10.37 & 8.87 & 0.10484 \\
\hline 4 & 35.02 & 48.40 & 94.21 & 80.83 & 13.38 & 0.75 & 0.02719 \\
\hline 5 & 48.32 & 61.70 & 80.91 & 67.53 & 13.38 & 0.16 & 0.00302 \\
\hline 6 & 61.32 & 74.70 & 67.91 & 54.53 & 13.38 & 0.40 & 0.00739 \\
\hline 7 & 74.42 & 87.80 & 54.81 & 41.43 & 13.38 & 0.15 & 0.00336 \\
\hline 8 & 86.82 & 100.20 & 42.41 & 29.03 & 13.38 & 0.38 & 0.00671 \\
\hline 9 & 96.82 & 110.20 & 32.41 & 19.03 & 13.38 & 0.19 & 0.00537 \\
\hline 10 & 106.92 & 120.30 & 22.31 & 8.93 & 13.38 & 0.28 & 0.00302 \\
\hline 11 & 117.32 & 130.70 & 11.91 & -1.47 & 13.38 & 0.50 & 0.01074 \\
\hline 12 & 127.32 & 140.70 & 1.91 & -11.47 & 13.38 & 0.24 & 0.00705 \\
\hline 13 & 137.32 & 150.70 & -8.09 & -21.47 & 13.38 & 0.27 & 0.00906 \\
\hline 14 & 147.12 & 160.50 & -17.89 & -31.27 & 13.38 & 1.05 & 0.02820 \\
\hline 15 & 157.12 & 170.50 & -27.89 & -41.27 & 13.38 & 0.30 & 0.00403 \\
\hline
\end{tabular}

where $K_{m}$ is the permeability coefficient of the section $(\mathrm{m} / \mathrm{s})$, $n$ is the number of cracks, $a_{m i}$ is the mechanic aperture $(m)$, $\mathrm{JRC}_{i}$ is the roughness coefficient, $\gamma$ is the volumetric weight $\left(\mathrm{N} / \mathrm{m}^{3}\right), \mu$ is the viscosity $(\mathrm{Pa} \cdot \mathrm{s})$, and $\theta_{i}$ is the inclination angle of the crack $\left(^{\circ}\right)$.

\section{Model Validation}

4.1. Calculation of Permeability Coefficient and Comparison with the Measurement Value. According to the actual drilling condition, the measured permeability coefficient is affected by both its own spatial characteristics and the stress from surrounding rocks. Neglecting other influential conditions, the permeability coefficient derived from the crack seepage model based on the borehole data needs to be constrained using the confining pressure which yields a certain level of attenuation. Therefore, based on the comparison of the permeability coefficients obtained from the crack model calculation and those measured from the water pressure test in the borehole (as shown in Table 1), we can estimate the extent to which the permeability coefficient is attenuated by the confining pressure. After integrating all data, the comparison charts are obtained, as shown in Figures 7 and 8.

As shown in Figure 7, the permeability coefficients calculated from the seepage model based on the borehole data are generally greater than the measured permeability coefficient. This is because the impact from the confining pressure on the crack aperture becomes greater with increasing confining pressure, which results in a decrease in the permeability coefficient. As each crack exhibits different levels of compressive deformation, the degree of change in the permeability coefficient is also different. However, the measured permeability coefficient is apparently larger at the borehole depth of $35.5 \mathrm{~m}$ and $160.5 \mathrm{~m}$. The fracture data for these two depth intervals are provided in Table 2, which indicates that the fracture aperture is essentially small and hence the measured permeability coefficient should be relatively low. Therefore, the apparently larger permeability coefficient measure may arise from two aspects: (1) the

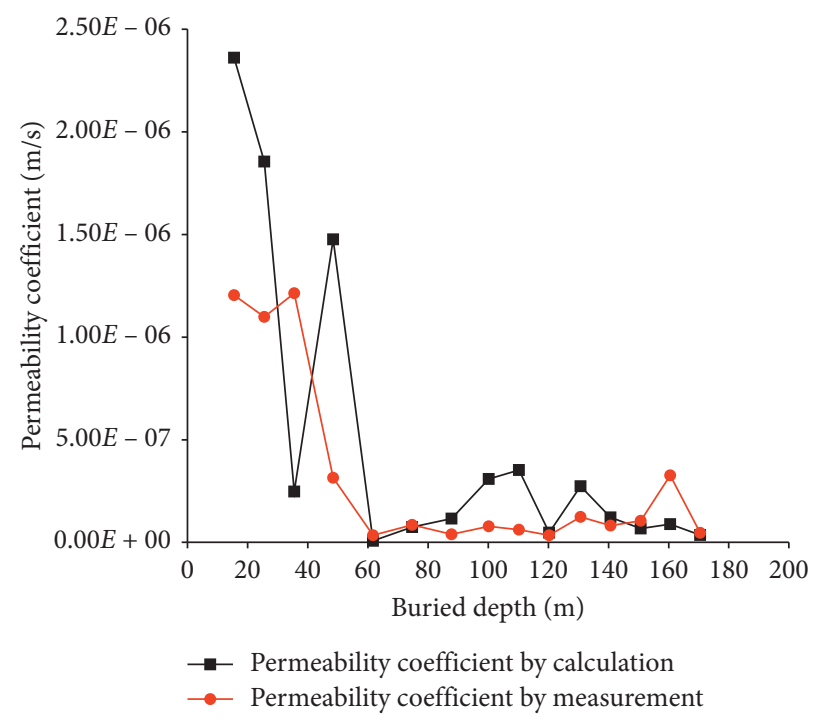

FIgURE 7: Comparison of the permeability coefficient by measurement and calculation.

hydraulic pressure test is not completely accurate and (2) some engineering operation in the borehole, such as flushing borehole, damages the original crack shape and results in inaccurate crack aperture and number.

Because the calculated and measured data are from different lengths of the study section, it is a little inconvenient to compare the permeability coefficient of the whole section of the borehole. A new parameter $K_{n}$ is defined to describe the permeability coefficient per unit depth:

$$
K_{n}=\frac{K_{m}}{H}
$$

where $K_{n}$ is the permeability coefficient per unit depth (/s), $K_{m}$ is the permeability coefficient of the section $(\mathrm{m} / \mathrm{s})$, and $H$ is the depth of the section (m).

In Figure 8, the comparison of the permeability coefficient per unit depth by calculation and measurement clearly highlights the relevance of the two results. 


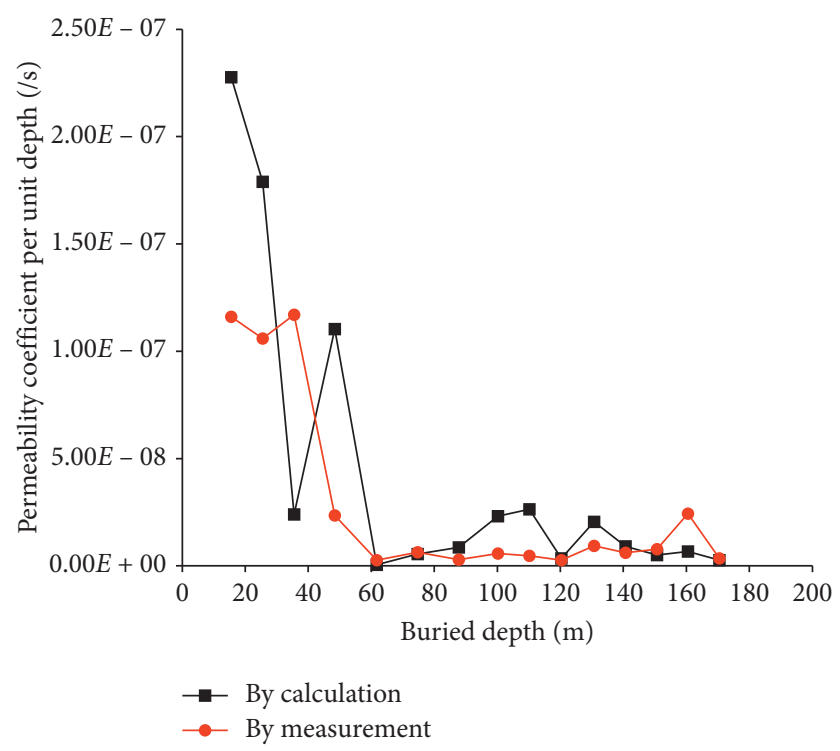

Figure 8: Permeability coefficient per unit depth with buried depth.

TABle 2: The fracture data for sections 3 and 14 of the borehole.

\begin{tabular}{|c|c|c|c|c|c|c|}
\hline \multirow{2}{*}{ Section no. } & \multicolumn{2}{|c|}{ Depth } & \multirow{2}{*}{ Length of test section (m) } & \multirow{2}{*}{ Inclination angle $\left({ }^{\circ}\right)$} & \multirow{2}{*}{ Inclination $\left(^{\circ}\right)$} & \multirow{2}{*}{ Aperture $(\mathrm{cm})$} \\
\hline & Start $(\mathrm{m})$ & End $(\mathrm{m})$ & & & & \\
\hline \multirow{16}{*}{3} & 25.193 & 25.203 & 0.01 & 24.61 & 240.37 & 1.044 \\
\hline & 25.377 & 25.495 & 0.118 & 57.53 & 128.49 & 0.217 \\
\hline & 25.737 & 25.89 & 0.153 & 63.96 & 359.45 & 0.391 \\
\hline & 25.845 & 26.06 & 0.215 & 70.76 & 358.89 & 0.391 \\
\hline & 25.895 & 26.086 & 0.191 & 68.51 & 359.45 & 0.261 \\
\hline & 26.083 & 26.266 & 0.183 & 67.77 & 358.89 & 0.174 \\
\hline & 26.453 & 26.564 & 0.111 & 56.14 & 275.82 & 0.174 \\
\hline & 27.331 & 27.544 & 0.213 & 70.57 & 359.45 & 0.217 \\
\hline & 28.761 & 28.954 & 0.193 & 68.77 & 358.89 & 0.261 \\
\hline & 29.203 & 29.488 & 0.285 & 75.25 & 270.83 & 0.348 \\
\hline & 33.176 & 33.24 & 0.064 & 40.64 & 94.15 & 0.435 \\
\hline & 33.657 & 33.72 & 0.063 & 40.06 & 137.35 & 0.217 \\
\hline & 33.675 & 33.739 & 0.064 & 40.45 & 175.57 & 0.217 \\
\hline & 33.716 & 33.804 & 0.088 & 49.65 & 189.42 & 0.217 \\
\hline & 33.859 & 33.902 & 0.043 & 29.61 & 151.2 & 0.217 \\
\hline & 34.479 & 34.547 & 0.068 & 42.32 & 96.37 & 0.261 \\
\hline \multirow{14}{*}{14} & 148.082 & 148.084 & 0.002 & 76.92 & 202.09 & 0.217 \\
\hline & 148.976 & 148.978 & 0.002 & 45.34 & 163.44 & 0.173 \\
\hline & 149.266 & 149.274 & 0.008 & 63.58 & 193.25 & 0.781 \\
\hline & 149.38 & 149.382 & 0.002 & 53.54 & 149.63 & 0.173 \\
\hline & 150 & 150.002 & 0.002 & 57.36 & 198.77 & 0.217 \\
\hline & 150.396 & 150.4 & 0.004 & 50.53 & 127.55 & 0.347 \\
\hline & 150.875 & 150.879 & 0.004 & 52.7 & 126.44 & 0.39 \\
\hline & 150.915 & 150.917 & 0.002 & 49.01 & 152.39 & 0.173 \\
\hline & 150.958 & 150.963 & 0.005 & 43.48 & 125.34 & 0.52 \\
\hline & 151.82 & 151.823 & 0.003 & 55.11 & 195.46 & 0.26 \\
\hline & 153.532 & 153.534 & 0.002 & 60.04 & 128.65 & 0.173 \\
\hline & 159.497 & 159.501 & 0.004 & 56.68 & 200.43 & 0.347 \\
\hline & 159.589 & 159.594 & 0.005 & 61.69 & 184.42 & 0.52 \\
\hline & 160.219 & 160.225 & 0.006 & 27.76 & 93.31 & 0.607 \\
\hline
\end{tabular}

4.2. Trend Analysis of the Permeability Coefficient. The confining pressure is the most direct and influential factor affecting seepage flow through cracks. The relationship between the confining pressure and the permeability coefficient has been studied by many domestic and international researchers. The relationship between the permeability coefficient per unit depth and confining pressure (or buried depth) should be built to contribute to the prediction 


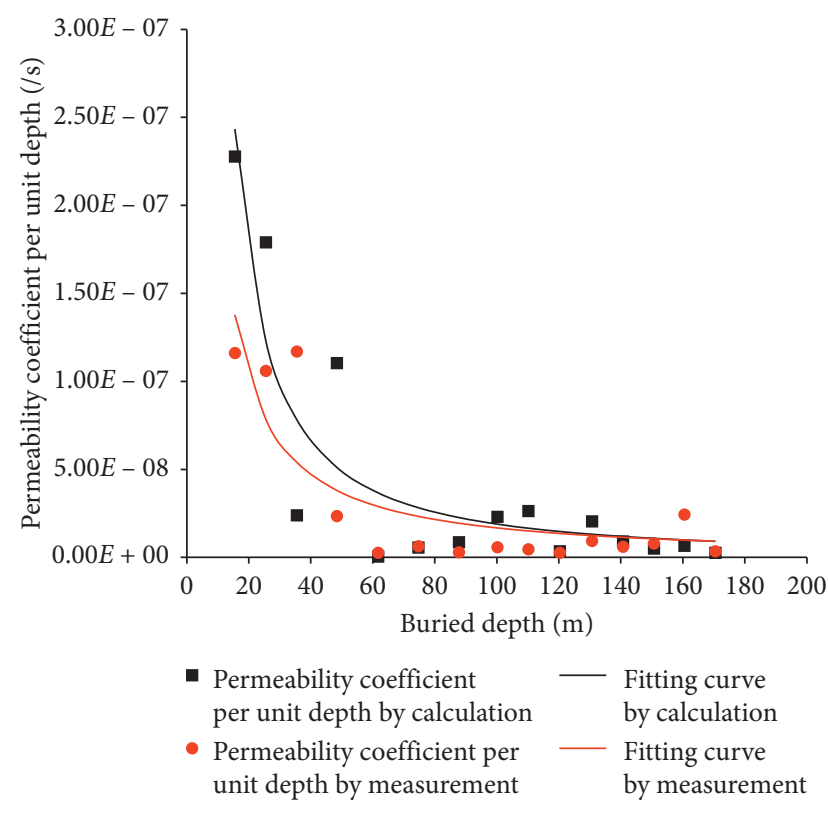

Figure 9: Comparison of fitting curves of the permeability coefficient per unit depth with buried depth.

of the permeability coefficient of different sections of a borehole.

The first study on this relationship was performed by Louis [23], who believed that normal stress has a considerable influence on the fracture surface while the influence of shear stress can be neglected. He tested the coupling relationship between normal stress and seepage flow and obtained an exponential relationship between the total stress and the permeability coefficient as a general conclusion. Later, the author revised this relationship and believed that "effective stress" should be used instead of total stress. In other words, there exists an exponential relationship between the effective stress and the permeability coefficient. Since then, many researchers have studied normal stress and seepage, and they have obtained a plethora of results. Currently, researchers believe that there exists a certain correlation between the stress and the permeability coefficient, which can be expressed by exponential, power, polynomial functions, etc. [24-28].

According to the previous research results, the data are fitted by power function, as shown in Figure 9.

The function of the fitting curve could be obtained by the software Origin, as illustrated in the following:

$$
\begin{aligned}
& y=1.04 \times 10^{-5} x^{-1.37}, \\
& y=3.05 \times 10^{-6} x^{-1.13}
\end{aligned}
$$

where function (12) is the fitting curve of the permeability coefficient per unit depth by calculation and function (13) is the fitting curve of the permeability coefficient per unit depth by measurement.

Thus, the permeability coefficient per unit depth evidently varies based on the buried depth in an approximate power function. The calculation data are larger than the measurement data in near-surface areas on account of lower confining pressure, which produces some error when the buried depth is smaller than $60 \mathrm{~m}$. However, it matched precisely when buried depth was greater than $60 \mathrm{~m}$.

Therefore, the aforementioned method can be used to estimate the permeability coefficient of any section in the well. Simultaneously, the permeability coefficient of the borehole can be estimated using the fracture characteristics in the borehole. If a large deviation of measured data from the calculated value arises, it is then necessary to conduct further studies to investigate the faults and caves around the borehole.

\section{Conclusions}

A method for estimating the permeability coefficient was proposed considering the aperture, inclination angle, and joint roughness coefficient. During the prefeasibility stage or under the condition with the limited borehole, the method could help reduce the number of hydraulic pressure tests and save a large amount of cost. Further work should be done on more drill holes to establish a theoretical model of generality.

The conclusions of the study are listed as follows:

(1) Based on the crack aperture, inclination angle, and JRC in the borehole data, we can estimate the seepage flow through the cracks in a target section. The estimated value reveals a similar trend to that of the measured permeability coefficient. The fitting curve of the permeability coefficient per unit depth with buried depth approximates a power function.

(2) During the prefeasibility stage, the permeability coefficient of the borehole can be estimated based on the fracture characteristics in the borehole. The permeability coefficients of different areas in boreholes can be estimated by the abovementioned method, which greatly reduces the number of hydraulic pressure tests and consequently reduces a lot of costs.

(3) The method could be used for the judgment of faults or caves. If there exists a large deviation between the measured data and the calculated value, it is necessary to further investigate the faults and caves around the borehole.

\section{Data Availability}

The borehole data used to support the findings of this study were supplied by China Petroleum Engineering \& Construction Corp, a North China Company under license, and so cannot be made freely available. Requests for access to these data should be made to XuZuo (zuoxu@cpeccnc.com).

\section{Conflicts of Interest}

The authors declare no conflicts of interest.

\section{Acknowledgments}

The authors appreciate the great help from China Petroleum Engineering \& Construction Corp, including field 
investigation, site experiments, and data collection. The authors would also like to express their gratitude to the National Natural Science Foundation of China (NSFC) for providing financial support for this work (authorized nos. 41972298 and 41877200 ). The project was also supported by the Fundamental Research Funds for the Central Universities, China University of Geosciences (Wuhan) (no. CUGL150818).

\section{References}

[1] B. Aberg, "Prevention of gas leakage from unlined reservoirs in rock," in Storage in Excavated Rock Caverns: Rockstore 77, pp. 399-413, Pergamon, Oxford, NY, USA, 1978.

[2] D. C. Goodall, Containment of gas in rock caverns, Ph.D. thesis, University of California, Berkley, CA, USA, 1986.

[3] G. M. Lomize, Flow in Fractured Rocks, Gosemergoizdat, Moscow, Russia, 1951.

[4] W. Xiang and H. Tang, Geotechnical Engineering Investigation, Chemical Industry Press, Beijing, China, 2012.

[5] C. E. Neuzil and J. V. Tracy, "Flow through fractures," Water Resources Research, vol. 17, no. 1, pp. 191-199, 1981.

[6] B. Amadei and T. Illangasekare, "A mathematical model for flow and solute transport in non-homogeneous rock fractures," International Journal of Rock Mechanics and Mining Sciences \& Geomechanics Abstracts, vol. 31, no. 6, pp. 719-731, 1994.

[7] B. Su, M. Zhan, and J. Zhao, "Study on fracture seepage in the limitative nature rock," Chinese Journal of Geotechnical Engineering, vol. 17, no. 5, pp. 19-24, 1995.

[8] L. Ding, "Experimental study on mechanics and seepage characteristics of single fracture," Master's thesis, Xi'an University of Technology, Xi'an, China, 2019.

[9] Z. Chuangbing, Z. Ye, and Bing Han, "A study on configulation and hydraulic conductivity of rock joints," $A d$ vances in Water Science, vol. 8, no. 3, pp. 233-239, 1997.

[10] W. Xiao, C. Xia, and W. Wang, "Study of void model for fluid flow through rough joint by considering 3D topography characteristics," Chinese Journal of Rock Mechanics and Engineering, vol. 30, no. 2, pp. 3786-3795, 2011.

[11] H. Zhou and H. Xie, "Approach to evolution of the shape of fluid flow in rocks by stochastic theory," Chinese Journal of Geotechnical Engineering, vol. 23, no. 2, pp. 183-186, 2001.

[12] X. Liu, E. Wang, S. Wang et al., "Representation method of fractured rock mass and its hydraulic properties study," Chinese Journal of Rock Mechanics and Engineering, vol. 27, no. 9, pp. 1814-1821, 2008.

[13] G. Zhang, C. Feng, and W. Gong, "Simulation and analysis of the effect of roughness elements on fluid flow through single fracture based on lattice Boltzmann method," Scientia Sinica Physica, Mechanica and Astronomica, vol. 47, no. 2, Article ID 024701, 2017.

[14] J. Sheng, F. Wang, X. Zhang et al., "Lattice Boltzmann method for rough fracture seepage characteristics of rock," Chinese Journal of Geotechnical Engineering, vol. 36, no. 7, pp. 12131217, 2014.

[15] H. Fan and H. Zheng, "MRT-LBM-based numerical simulation of seepage flow through fractal fracture networks," Science China Technological Sciences, vol. 56, no. 12, pp. 3115-3122, 2013.

[16] Y. Tan, Y. Yin, G. Teng et al., "Simulation research of gas seepage based on Lattice Boltzmann method," Journal of China Coal Society, vol. 39, no. 8, pp. 1446-1454, 2014.
[17] L. Sheng, Y. Zeng, Zhiliang, and S. Li, "Research on seepage properties of rough fracture considering geometrical morphology," Chinese Journal of Rock Mechanics and Engineering, vol. 38, no. 1, pp. 2704-2711, 2019.

[18] M. Liang, "Numerical simulation study of flow in single rough fractures based on fluent," Master's thesis, Hefei University of Technology, Hefei, China, 2010.

[19] D. T. Snow, A parallel plate model of fractured permeable media, Ph.D thesis, University of California, Oakland CA, USA, 1965.

[20] D. T. Snow, "Anisotropie permeability of fractured media," Water Resources Research, vol. 5, no. 6, pp. 1273-1289, 1969.

[21] N. Barton, Modelling Rock Joint Behavior from in Situ Block Tests: Implications for Nuclear Waste Repository Design, Vol. 308, Office of Nuclear Waste Isolation, Columbus, $\mathrm{OH}$, USA, 1982.

[22] N. Barton and S. Bandis, "Review of predictive capabilities of JRC-JCS model in the engineering practice," in Proceedings of the Rock Joints, pp. 603-610, Loen, Norway, June 1990.

[23] C. Louis, Rock Hydraulics Rock Mechanics, L Müller.SpringerNew Verlag, New York, USA, 1974.

[24] D. T. Snow, "Rock fracture spacings, openings, and porosities," Journal of Soil Mechanisms and Foundations Division, vol. 94, no. 1, pp. 73-91, 1968.

[25] F. O. Jones, "A laboratory study of the effects of confining pressure on fracture flow and storage capacity in carbonate rocks," Journal of Petroleum Technology, vol. 27, no. 01, pp. 21-27, 1975.

[26] J. E. Gale, "The effects of fracture type (induced versus natural) on the stress-fracture closure-fracture permeability relationships," in Proceedings of the 23rd US Symposium on Rock Mechanics (USRMS), American Rock Mechanics Association, Berkeley, CA, USA, August 1982.

[27] R. L. Kranzz, A. D. Frankel, T. Engelder, and C. H. Scholz, "The permeability of whole and jointed Barre granite," International Journal of Rock Mechanics and Mining Sciences \& Geomechanics Abstracts, vol. 16, no. 4, pp. 225-234, 1979.

[28] Y. Wang and B. Y. Su, "Research on the behavior of fluid flow in a single fracture and its equivalent hydraulic aperture," Advances Water Science, vol. 13, no. 1, pp. 61-68, 2002. 